\title{
Lithium-induced neuroprotection is associated with epigenetic modification of specific BDNF gene promoter and altered expression of apoptotic-regulatory proteins
}

\section{Tushar Dwivedi and Hui Zhang*}

Department of Psychiatry, University of Illinois at Chicago, Chicago, IL, USA

\section{Edited by:}

Ashok Kumar, University of Florida USA

\section{Reviewed by:}

Gianluca Serafini, Sapienza

University of Rome, Italy

Paramita Chakrabarty, University of

Florida, USA

\section{*Correspondence:}

Hui Zhang, Department of

Psychiatry, University of Illinois at

Chicago, 1601 West Taylor Street,

Chicago, IL 60612, USA

e-mail: hzhang326@uic.edu

\begin{abstract}
Bipolar disorder (BD), one of the most debilitating mental disorders, is associated with increased morbidity and mortality. Lithium is the first line of treatment option for BD and is often used for maintenance therapy. Recently, the neuroprotective action of lithium has gained tremendous attention, given that BD is associated with structural and functional abnormalities of the brain. However, the precise molecular mechanism by which lithium exerts its neuroprotective action is not clearly understood. In hippocampal neurons, the effects of lithium ( 1 and $2 \mathrm{mM}$ ) on neuronal viability against glutamate-induced cytotoxicity, dendritic length and number, and expression and methylation of BDNF promoter exons and expression of apoptotic regulatory genes were studied. In rat hippocampal neurons, lithium not only increased dendritic length and number, but also neuronal viability against glutamate-induced cytotoxicity. While lithium increased the expression of BDNF as well as genes associated with neuroprotection such as $\mathrm{Bcl} 2$ and $\mathrm{Bcl}-\mathrm{XL}$, it decreased the expression of pro-apoptotic genes Bax, Bad, and caspases 3. Interestingly, lithium activated transcription of specific exon IV to induce BDNF gene expression. This was accompanied by hypomethylation of BDNF exon IV promoter. This study delineates mechanisms by which lithium mediates its effects in protecting neurons.
\end{abstract}

Keywords: lithium, bipolar, BDNF, apoptotic regulatory genes, methylation, hippocampal culture

\section{INTRODUCTION}

Bipolar disorder (BD) is one of the most debilitating disorders, which affects about $1 \%$ of the population in the world (Schroeder et al., 2011). Among various mental disorders, BD is associated with the highest risk of suicide (Nock et al., 2009), characterized by often cyclothymic and irritable temperaments, which leads to increased risk of suicide up to 20 times that of the average population (Pompili et al., 2013).

Several clinical studies suggest that BD is associated with changes in the brain structure and imbalance in signal transduction mechanisms that can lead to altered cellular integrity and synaptic plasticity. For example, a magnetic resonance spectroscopy (MRS) study demonstrates that BD is associated with neuronal and glial stress, neuronal atrophy, and cell death (Glitz et al., 2002). Further, bipolar patients show reduced gray matter volume in medial prefrontal cortex, amygdala, and ventral and orbitofrontal cortices (Brambilla et al., 2005). In addition, reduction in neuronal size and changes in neuronal density in medial prefrontal cortex of bipolar patients have been reported (Savitz et al., 2014). MRS studies also demonstrate that cellular signaling pathways that are critical for neuronal protection are significantly altered in prefrontal cortex, anterior cingulate cortex, and hippocampus of bipolar patients (Yildiz-Yesiloglu and Ankerst, 2006; Visnjic and Banfic, 2007).

Several studies suggest that brain-derived neurotrophic factor (BDNF), a protein involved in neuronal survival, dendritic branching, and synaptic plasticity (Huang and Reichardt, 2001), is lower in the brain and serum of bipolar patients (Cunha et al., 2006; Monteleone et al., 2008). Lower BDNF gene expression in bipolar patients could be associated with epigenetic modifications (D'Addario et al., 2012; Gao et al., 2012). BDNF mediates its neurotrophic action after binding to and activating tropomycinreceptor kinase B (TrkB). This leads to signaling cascade of events within neurons, mediated by extracellular signal-regulated kinases (ERKs) and phosphoinositide 3-kinase (PI3K) (Huang and Reichardt, 2001). Interestingly, it has been shown that not only is the activation of TrkB less active in the brain of bipolar patients but ablation of ERK activation can leads to hyperactivity in rodents (Engel et al., 2009). In addition, an association between AKT1 genetic variants and $\mathrm{BD}$ has been shown which increases the suicidal risk in these patients (Karege et al., 2010; Magno et al., 2010). One of the major functions of BDNF-mediated ERK $1 / 2$ and PI 3-K/Akt signaling is to regulate proteins involved in cell survival. This occurs via the Bcl-2 family of proteins and the cysteine protease caspase family. $\mathrm{Bcl} 2$ family proteins are divided into two groups: anti-apoptotic $\left(\mathrm{Bcl} 2\right.$ and $\left.\mathrm{Bcl}_{\mathrm{L}}\right)$ and pro-apoptotic (Bax and Bak, Bid, Bad, and Bim) (Lucken-Ardjomande and Martinou, 2005). Pro-death Bcl2 family members initiate a cell death program, which involves opening of the mitochondrial permeability pore, decreases in the mitochondrial membrane potential, and the release of cytochrome $\mathrm{C}$. This results in the nucleation of apoptosome, comprised of Apaf- 1 , cytochrome c, 
and caspase 9, which then cleaves and activates caspase-3, the main executioner of the apoptotic cascade (Yuan and Yankner, 2000). Bclx $\mathrm{L}_{\mathrm{L}}$ binds to Apaf-1 and blocks the ability of Apaf-1 to activate pro-caspase 9 which is antagonized by Bax (SchulzeOsthoff et al., 1998). The $\mathrm{Bcl} 2$ gene contains a CRE-binding site and activation of CREB via ERK1/2 can lead to increased synthesis of $\mathrm{Bcl} 2$ gene (Wilson et al., 1996). Expression of $\mathrm{Bcl}-\mathrm{x}_{\mathrm{L}}$ is regulated by $\mathrm{p} 90 \mathrm{RSK}$ in response to ERK1/2 activation. A recent study shows polymorphism in Bcl-2 gene (rs956572) in BD patients (Soeiro-de-Souza et al., 2013). In addition, decreased density of neurons and glia and decreased size of neurons in frontal and subcortical areas of bipolar brain could be due to increased apoptosis (Gigante et al., 2011).

Lithium is the most effective mood stabilizer and is the first line of treatment for BD (Rybakowski, 2011). Though lithium is a highly prescribed medicine, its mechanism of action is not clear. Several lines of studies suggest that clinical efficacy of lithium is related to its effects on neuroprotection. This is evident from studies showing increased total gray matter content (Moore et al., 2000a) and enhanced levels of $N$-acetyl-aspartate, a marker of neuronal viability, by lithium in the brain of bipolar patients (Moore et al., 2000b). Bipolar patients, who are exposed to lithium, also have greater amygdala gray volume (Chang et al., 2005). Recently, Gildengers et al. (2014) reported that longer duration of lithium treatment is associated with higher white matter integrity. Similarly, the loss of the subgenual prefrontal cortex volume found in bipolar patients is suppressed in patients receiving lithium (Drevets, 2001). Given that lithium's neuroprotective action could be associated with clinical improvement, it is imperative to examine how lithium acts to protect neurons.

The present study aims to delineate such mechanisms. It is hypothesized that (1) lithium will protect neurons by increasing neuronal viability, dendritic length, and dendritic number, (2) lithium will increase the expression of BDNF gene and differentially regulate the expression of pro- and anti-apoptotic proteins, and (3) the effect of lithium on BDNF will be exon specific and will be epigenetically regulated.

\section{MATERIALS AND METHODS \\ NEURONAL CULTURE AND LITHIUM TREATMENT}

Cryopreserved rat hippocampal neurons were obtained from UIC Research Resource Center (Chicago, IL) as a SPOT culture kit (provided by Dr. Lech Kiedrowaski). Neurons were suspended in neurobasal medium (Invitrogen, CA). The medium was supplemented with $1 \mathrm{mM}$ glutamine and 1\% B27 (Invitrogen, CA) and seeded onto culture adhesive coated surfaces provided with the Spot kit and kept in $\mathrm{CO}_{2}$ chamber at $37^{\circ} \mathrm{C}$. After 3 days, $1 \mathrm{mM}$ glutamine was replaced by $1 \mathrm{mM}$ glutamax (Invitrogen, CA) in the culture medium. Seven days later, lithium chloride (Sigma, $\mathrm{MO}$ ) was added to the culture medium to give the final concentration of 1 or $2 \mathrm{mM}$. Another group of neurons was treated with normal saline $\left(0.9 \% \mathrm{NaCl}_{2}\right.$ in phosphate buffer saline). Neuronal cells were pretreated with lithium or normal saline for $36 \mathrm{~h}$ prior to the addition of glutamate $(100 \mu \mathrm{M})$ for $12 \mathrm{~h}$. Neuronal viability and morphology were studied. A separate set of neurons were treated with lithium ( 1 or $2 \mathrm{mM}$ ) for $48 \mathrm{~h}$ and the expression of BDNF as well as pro and anti-apoptotic genes was examined.

\section{NEURONAL VIABILITY}

Neuronal viability was assessed using MTT (3-(4,5dimethylthiazol-2-yl)-2,5-diphenyltetrazolium bromide) reduction assay kit (Sigma, MO). MTT $(0.5 \mathrm{mg} / \mathrm{ml})$ was added to the culture medium (at a ratio of $1: 10$ ) after $48 \mathrm{~h}$ of lithium treatment. After $2 \mathrm{~h}$ incubation, the medium was taken out; formazon product was dissolved in dimethylsulfoxide; absorbance was measured at $570 \mathrm{~nm}$ and neuronal viability was calculated. The results are expressed as a percentage of viability of the control culture.

\section{IMMUNOFLUORESCENCE STAINING OF CULTURED NEURONS}

To determine the effect of lithium on neuronal morphology, neuron cultures were fixed with $4 \%$ paraformaldehyde for $30 \mathrm{~min}$ at room temperature, permeabilized with $0.25 \%$ Triton X-100 in phosphate buffer saline for $10 \mathrm{~min}$, blocked with $5 \%$ donkey serum (Jackson Laboratories, PA) for $1 \mathrm{~h}$ at room temperature, and then incubated for $16 \mathrm{~h}$ at $4^{\circ} \mathrm{C}$ with rabbit anti-microtubuleassociated protein (MAP)2 antibody (Millipore, MA). Dilution of antibody was 1:1000. This was followed by incubation with fluorescein labeled donkey anti-rabbit IgG (1:200) (Jackson Laboratories, PA) for $1 \mathrm{~h}$ at room temperature. After washing in phosphate buffer saline, coverslips were inverted in slides over a drop of vectashield mounting medium for fluorescence with $4^{\prime}, 6$ Diamidino-2-phenylindole (DAPI) (Vector Labs, CA). Images were obtained at $40 \times$ magnification using the camera attached to the microscope.

\section{ASSAYS FOR DENDRITIC OUTGROWTH AND NEUROPROTECTIVE ACTIVITY}

Ten photographs per well were obtained from three wells for each group. Thirty well-stained neurons that made connections to no more than two cells were selected for measurements of their primary dendritic length and dendritic number. Dendrites were defined as processes with a length longer than the cell diameter. Dendritic length was measured by the software from Neurolucida (MBF Bioscience, VT), whereas the percentage of cells forming dendrites was calculated.

\section{DETERMINATION OF mRNA EXPRESSION OF BDNF, BCL2, Bcl- $X L$, Bad, Bax, Caspase 3 BY REAL TIME-REVERSE TRANSCRIPTASE POLYMERASE CHAIN REACTION (RT-PCR)}

RNA from hippocampal neurons were isolated using Trizol kit (Life Technologies, CA). The RNA yield and the ratio of absorbance at 260 to $280 \mathrm{~nm}\left(\mathrm{~A}_{260} / \mathrm{A}_{280}\right.$ ratio $)$ were measured with the NanoDrop ${ }^{\circledR}$ Spectrophotometer (Thermo Scientific, DE). mRNA levels of various genes were determined using a two-step qPCR (Stratagene Mx3005p). One $\mu$ g of total RNA was reverse transcribed using $50 \mathrm{ng}$ random hexamers, $2 \mathrm{mM} \mathrm{dNTP}$ mix, $10 \mathrm{u}$ ribonuclease inhibitor, and $200 \mathrm{u}$ MMLV-reverse transcriptase in a final reaction volume of $20 \mu \mathrm{l}$. The primer/probe sets were obtained from Applied Biosystems as the TaqMan Gene Expression Assay kit. The PCR reaction was carried out in a final volume of $20 \mu \mathrm{l}$, containing $5 \mu \mathrm{l}$ of $\mathrm{cDNA}$ diluted $1: 10,1 \times$ of TaqMan primer/probe mix $(20 \times)$, and $1 \times$ TaqMan ${ }^{\circledR}$ Universal PCR master mix. For each primer/probe tested, the PCR reaction also included a non-reverse transcription negative control to 
confirm the absence of genomic DNA, a non-template negative control to check for primer-dimer. The amounts of target genes expressed in a sample were normalized to GAPDH. Fold changes between subject groups are measured using the $2^{-\Delta \Delta \mathrm{Ct}}$ method, where $\Delta \Delta \mathrm{C}_{\mathrm{T}}=\left(\mathrm{C}_{\text {Ttarget }}-\mathrm{C}_{\text {Tnormalizer }}\right)_{\text {sample }}-\left(\mathrm{C}_{\text {Ttarget }}-\right.$ $\left.\mathrm{C}_{\text {Tendogenousgene }}\right)_{\text {control }}$.

\section{QUANTITATION OF BDNF PROTEIN BY WESTERN BLOT}

Gel electrophoresis and immunolabeling of BDNF were performed by Western blot. Primary neuronal culture cells were homogenized in a Tris buffer containing $5 \mathrm{mM}$ EDTA, $1 \mathrm{mM}$ phenylmethylsulfonyl fluoride, $5 \mu \mathrm{g} / \mathrm{ml}$ each of aprotinin, leupeptin, pepstatin, and $10 \mu \mathrm{g} / \mathrm{ml}$ of $100 \mathrm{mM}$ sodium orthovanadate. Equal volumes of samples containing $10 \mu \mathrm{g}$ of protein were electrophoresed on $10 \%(\mathrm{w} / \mathrm{v})$ polyacrylamide gel. The blots were incubated overnight at $4^{\circ} \mathrm{C}$ with primary antibody for BDNF (1:1000 dilution; RandD Systems, MN) followed by horseradish-peroxidase-linked secondary anti-mouse or anti-rabbit IgG (1:1000 dilution; GE Healthcare Bio-Sciences, Piscataway, $\mathrm{NJ}$ ) for $5 \mathrm{~h}$ at room temperature. The membranes were stripped and re-probed with $\beta$-actin monoclonal primary (1:5000 for $1 \mathrm{~h}$, Sigma Chemical Co., St. Louis, MO) and antimouse secondary antibody (1:5000 for $1 \mathrm{~h})$. The bands on the autoradiograms were quantified using the Loats Image Analysis System (Westminister, MD). The optical density (O.D.) of each protein was corrected by the optical density of the corresponding $\beta$-actin band. The results are presented as percent of control.

\section{MRNA EXPRESSION OF BDNF EXONS}

RNA was reverse transcribed using the iScript RT-PCR iQ SYBR Green Supermix (Bio-Rad, Hercules, CA). RT-PCR amplifications were carried out at $50^{\circ} \mathrm{C}$ for $30 \mathrm{~min}$; $95^{\circ} \mathrm{C}$ for $15 \mathrm{~min}$ followed by $40 \mathrm{cycles}$ of $94^{\circ} \mathrm{C}$ for $60 \mathrm{~s} ; 57^{\circ} \mathrm{C}$ for $60 \mathrm{~s} ; 72^{\circ} \mathrm{C}$ for $60 \mathrm{~s}$ and then incubation at $70^{\circ} \mathrm{C}$ for $10 \mathrm{~min}$, using primers specific to the rat BDNF exons (I, II, IV, and VI) as described in Table 1. $\beta$-Actin was used as normalizer.

\section{METHYLATION-SPECIFIC RT-PCR FOR BDNF EXON PROMOTER METHYLATION}

DNA was isolated from hippocampal neurons, purified and processed for bisulfite modification (Lubin et al., 2008). Methylationspecific PCR primers are provided in Table 2 . $\beta$-actin DNA was evaluated as control. PCR reactions were performed using the following cycling conditions: $95^{\circ} \mathrm{C}$ for $3 \mathrm{~min}, 40$ cycles of $95^{\circ} \mathrm{C}$ for $15 \mathrm{~s}$ and $58-60^{\circ} \mathrm{C}$ for $1 \mathrm{~min}$. Samples were normalized to $\beta$-actin and the comparative $\mathrm{Ct}$ method was used to calculate differences in gene expression between samples.

\section{STATISTICAL ANALYSIS}

Each value is expressed as the mean \pm standard deviation (SD). The data were analyzed by SPSS software (Chicago, IL). Statistical differences between each group were evaluated by One-Way analysis of variance (ANOVA) followed by Bonferroni correction. Differences were considered significant at $p<0.05$.

\section{RESULTS \\ NEURONAL DEATH AFTER GLUTAMATE TREATMENT AND ITS PREVENTION BY LITHIUM}

To examine whether lithium is neuroprotective, lithium (1 or $2 \mathrm{mM}$ ) was added in the culture medium $36 \mathrm{~h}$ prior to glutamate $(100 \mu \mathrm{M})$ addition for $12 \mathrm{~h}$ and neuronal viability was assessed. Glutamate reduced the neuronal viability by $60 \%$ (Figure 1). It was found that this neuronal death was prevented by lithium in a dose-dependent manner. A dose of $1 \mathrm{mM}$ lithium increased the neuronal viability by $75 \%$ whereas $2 \mathrm{mM}$ lithium completely reversed glutamate-induced neuronal death (Figure 1).

Table 1 | Primer sequences for BDNF exons.

BDNF exon I mRNA: CTCAAAGGGAAACGTGTCTCT

TCACGTGCTCAAAAGTGTCAG

BDNF exon II mRNA: CTAGCCACCGGGGTGGTGTAA

TCACGTGCTCAAAAGTGTCAG

BDNF EXon IV mRNA: TGCGAGTATTACCTCCGCCAT

TCACGTGCTCAAAAGTGTCAG

BDNF exon VI mRNA: TTGGGGCAGACGAGAAAGCGC

TCACGTGCTCAAAAGTGTCAG

Table 2 | Methyl-specific Real-time PCR Primers.

BDNF exon I Methylated

CGGAAAGTATTAGAGGTAGGGTAGC

TACGAACCCTAAATCTCTAAACGAA

BDNF exon II Methylated

TCGTTGTTAAGTTAATTCGGTGTC

AAACTAAAACTAACTCTCCAAACGCT

BDNF exon IV Methylated

GGTAGAGGAGGTATTATATGATAGTTTACG

TAAATAAAAAAAACGACAACGCGAA

BDNF exon VI Methylated

ATTTTTCGGTTTGGAGAAGGAAATC

TCAAAATCCACACAAAACTCTCGAA

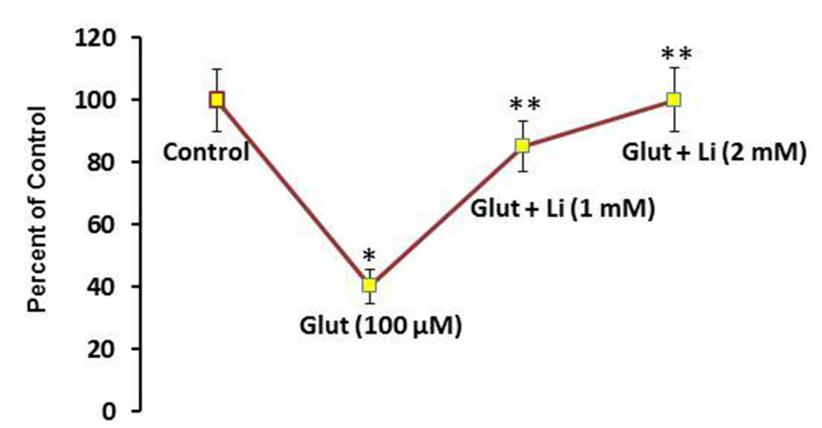

FIGURE 1 | Pretreatment of lithium prevents neuronal death by glutamate. Lithium (1 or $2 \mathrm{mM}$ ) was added to the medium $36 \mathrm{~h}$ prior to glutamate treatment. Glutamate $(100 \mu \mathrm{M})$ was added $12 \mathrm{~h}$ prior to examining neuronal viability. The data are mean \pm SD from 3 independent experiments. ${ }^{*} P<0.001$ compared with control group and ${ }^{* *} p<0.001$ compared with glutamate treated group. 


\section{EFFECT OF LITHIUM ON DENDRITIC LENGTH AND NUMBER}

Morphology of hippocampal neurons was studied in the control group (no treatment) and after glulatmate $(100 \mu \mathrm{M}$ for $12 \mathrm{~h})$ or glulatamate + lithium ( 1 or $2 \mathrm{mM}$ for $48 \mathrm{~h}$ ) treatment. The morphology of neurons was detected using MAP2 antibody, followed by treatment with DAPI (Figure 2). It was observed that the average dendrite length in the control group was $120.51 \pm$ $12.13 \mu \mathrm{m}$. The average dendritic length in the glutamate group was $81.45 \pm 16.12$. When $1 \mathrm{mM}$ of lithium was added, the average dendrite length increased to $100.64 \pm 12.11 \mu \mathrm{m}$. Finally, when $2 \mathrm{mM}$ lithium was added, the dendrite length increased to $117.51 \pm 17.10 \mu \mathrm{m}$ (Figure 3).

When dendrite numbers were compared, it was observed that the average number of dendrites per cell in the control group was $4.0 \pm 0.32$. Addition of glutamate reduced the dendritic number to $2.2 \pm 0.12$. The average number of dendrites per cell in glutamate $+1 \mathrm{mM}$ lithium group was $4.4 \pm 0.51$, whereas in glutamate $+2 \mathrm{mM}$ lithium group, it was $4.5 \pm 0.62$ (Figure 4).

\section{EFFECT OF LITHIUM ON mRNA AND PROTEIN EXPRESSION OF BDNF}

Lithium at $1 \mathrm{mM}$ concentration increased mRNA expression of BDNF. The mRNA expression of BDNF was increased by $67 \%$ whereas this effect was further substantiated (100\%) at $2 \mathrm{mM}$ lithium (Figure 5A). A Western blot showing expression of BDNF is provided in Figure 5B. When quantitatively assessed, the protein level of BDNF was significantly increased by both 1 and $2 \mathrm{mM}$ concentrations of lithium (Figure 5C). This increase was 53 and $89 \%$ for 1 and $2 \mathrm{mM}$ lithium, respectively.

\section{EFFECT OF LITHIUM ON EXPRESSION OF SPECIFIC BDNF PROMOTER AND METHYLATION OF PROMOTER EXONS}

To examine whether BDNF expression induced by lithium is associated with specific BDNF promoter(s), mRNA level of various exons (I, II, IV, and VI) were examined. It was observed that at $1 \mathrm{mM}$, lithium increased exon IV expression by $55 \%$ whereas at $2 \mathrm{mM}$, this increase was $98 \%$. There was no significant change in the expression of exons I, II, and VI by lithium (Figure 6).

\section{DNA METHYLATION OF BDNF GENE PROMOTERS BY LITHIUM}

To examine whether the effect of lithium is epigenetically regulated, methylation of exons I, II, IV, and VI was examined. At

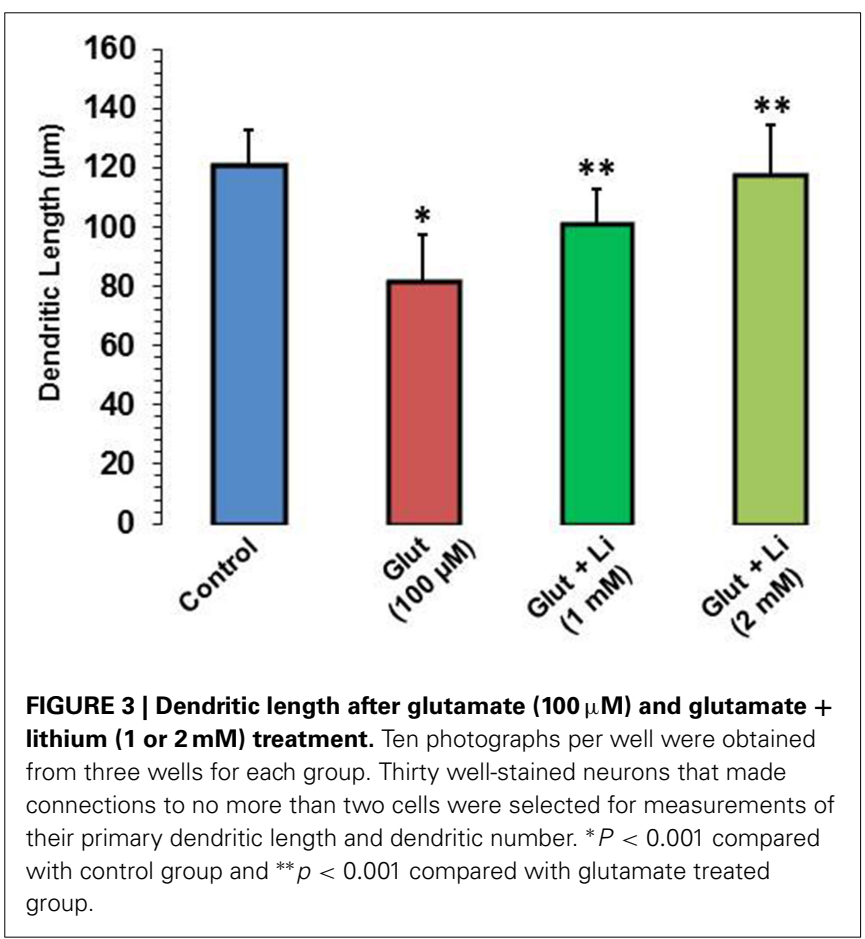

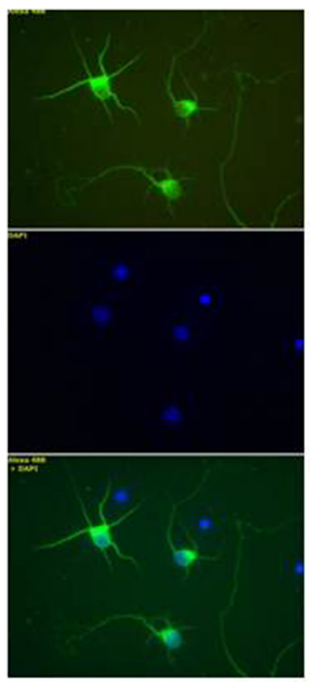

Control

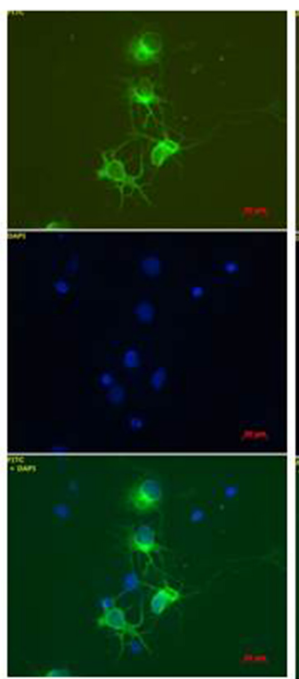

Glut (100 $\mu \mathrm{M})$
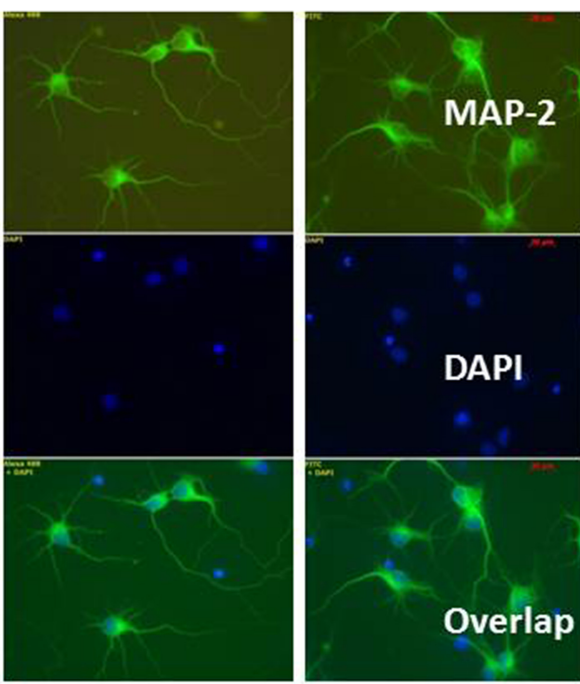

Glut + Li (1 mM)

Glut + Li (2 mM)

FIGURE 2 | Neuronal morphology after glutamate $(\mathbf{1 0 0} \mu \mathbf{M})$ and glutamate + lithium (1 or $\mathbf{2}$ mM) treatment. Treatment of glutamate and lithium was the same as mentioned in Figure $\mathbf{1 .}$ 
the dose of $1 \mathrm{mM}$, lithium decreased methylation of exon IV by $38 \%$, whereas at the dose of $2 \mathrm{mM}$, this decrease was $50 \%$. Methylation of promoters I, II, and VI was not affected by lithium (Figure 7).

\section{EFFECT OF LITHIUM ON EXPRESSION OF PRO- AND ANTI-APOPTOTIC GENES}

As can be seen in Figure 8A, lithium increased the expression of $\mathrm{Bcl} 2$ ( $1 \mathrm{mM}$ of lithium: $1.57 \pm 0.15$ fold; $2 \mathrm{mM}$ lithium: $1.83 \pm$ 0.12 fold $)$ and Bcl-XL ( $1 \mathrm{mM}$ of lithium: $1.17 \pm 0.06$ fold; $2 \mathrm{mM}$ : $1.43 \pm 0.12$ fold) in a dose dependent manner. Lithium did

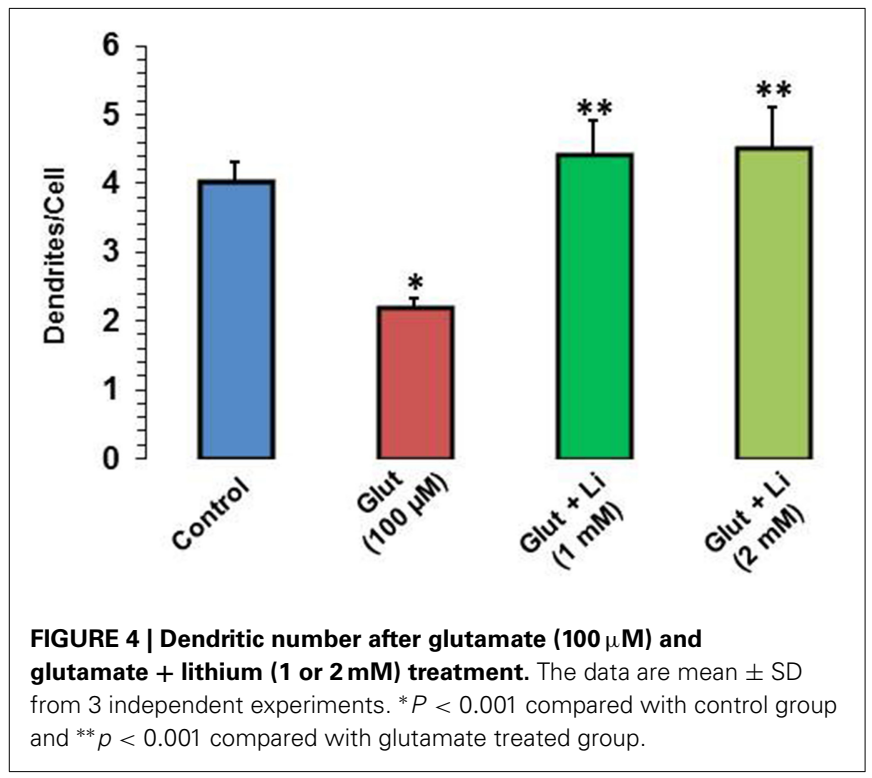

not show any change in the expression of Bax at $1 \mathrm{mM}$ dose but decreased its expression $(0.80 \pm 0.10$ fold) (Figure 8B). The expression of $\mathrm{BAD}$ was decreased by both doses of lithium, the magnitude of change being higher at $2 \mathrm{mM}(1 \mathrm{mM}$ lithium: $0.60 \pm 0.00$ fold; $2 \mathrm{mM}$ of lithium: $0.27 \pm 0.06$ fold) (Figure $8 B$ ). Finally, caspase 3 expression was also decreased by both doses of lithium, higher dose being more effective that the lower dose ( $1 \mathrm{mM}$ lithium: $0.57 \pm 0.06$ fold; $2 \mathrm{mM}$ lithium: $0.33 \pm 0.06$ fold) (Figure 8B).

\section{DISCUSSION}

In the present study, we used two different doses of lithium: $1 \mathrm{mM}$, which is in the clinical range, and $2 \mathrm{mM}$, which is slightly higher than the clinical range (reviewed in Young, 2009). Although higher dose has clinical side effects, we wanted to

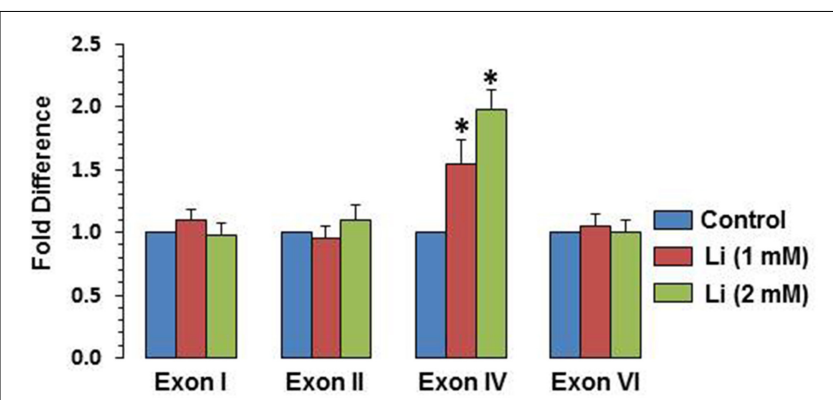

FIGURE 6 | Effect of lithium (1 or $\mathbf{2} \mathrm{mM}$ ) on expression of individual BDNF exons after $48 \mathrm{~h}$ after lithium (1 or $2 \mathrm{mM}$ ) treatment. The data are mean \pm SD from 3 independent experiments. ${ }^{*} P<0.001$ compared with control group.

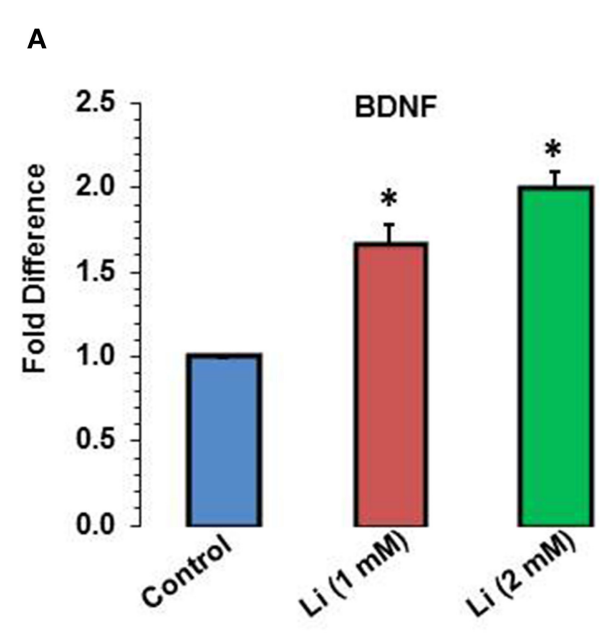

B

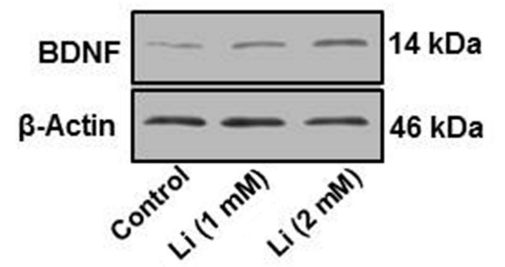

C

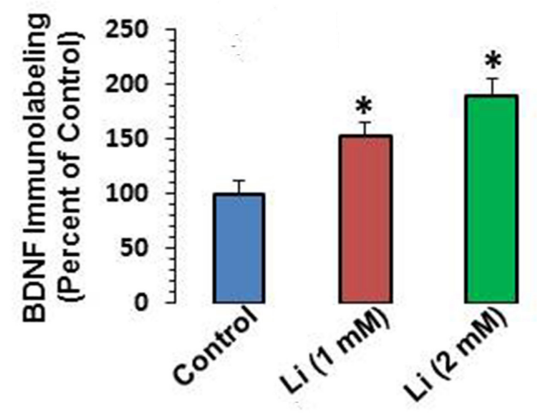

diagram showing effect of lithium on protein expression of BDNF. The results are presented as percent of control. The data are mean $\pm \mathrm{SD}$ from 3 independent experiments. ${ }^{*} P<0.001$ compared with saline treated group. 


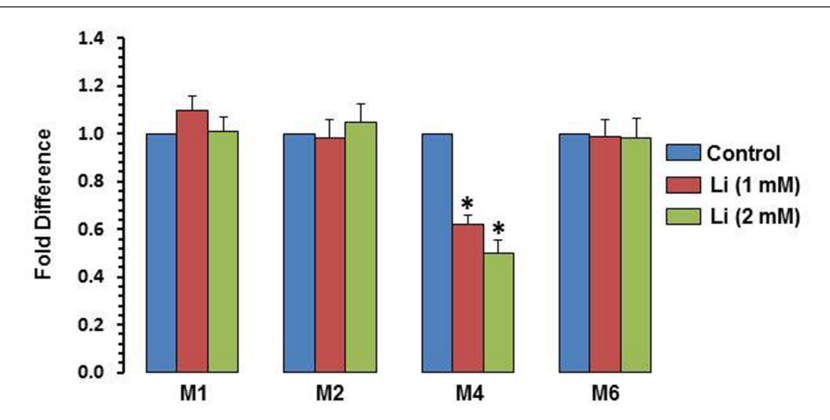

FIGURE 7 | DNA methylation of BDNF exons after $48 \mathrm{~h}$ of lithium (1 or $\mathbf{2} \mathbf{~ m M}$ ) treatment. The data are mean \pm SD from 3 independent experiments. ${ }^{*} P<0.001$ compared with control group.

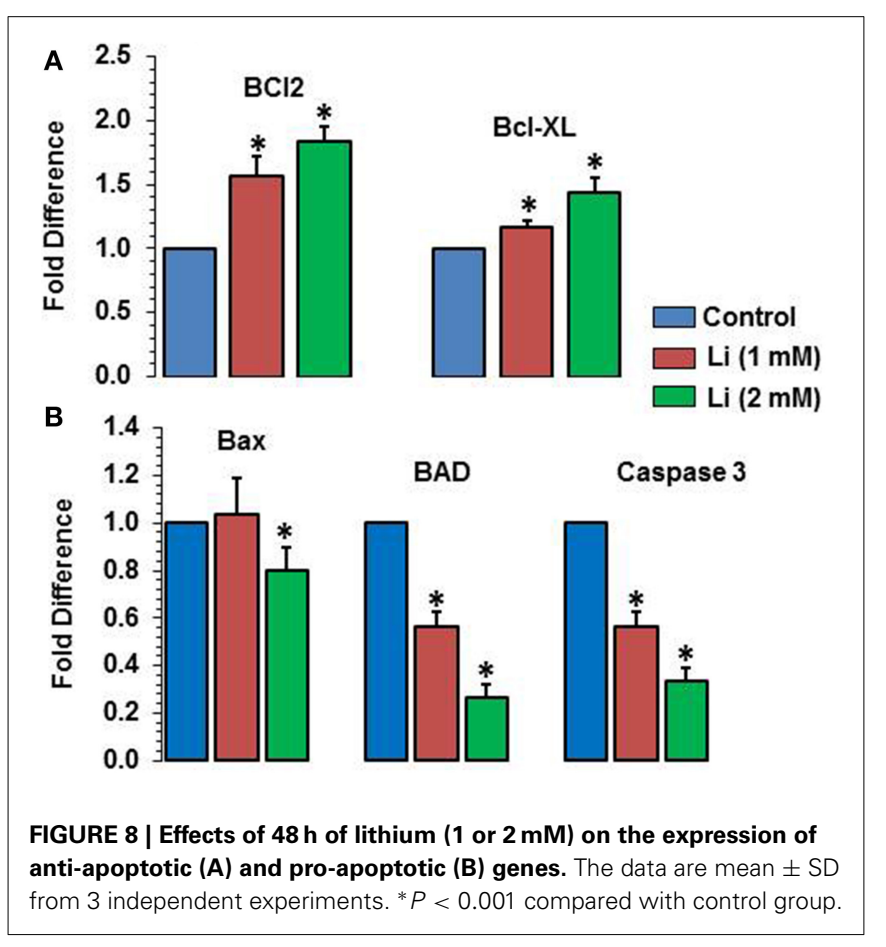

examine whether the side effects are associated with lithium neurotoxicity. Interestingly, this higher dose $(2 \mathrm{mM})$ has been shown to be neuroprotective against amelospheroid-induced toxicity in rat forebrain cholinergic neurons (Hoshi et al., 2003). The neuroprotective action of lithium was tested against glutamateinduced neurotoxicity (Hassel and Dingledine, 2006), which has been shown to be increased in CSF, plasma, and serum (Hoekstra et al., 2006) as well as in brain (Hashimoto et al., 2007) of bipolar patients. Abnormalities in the expression of glutamate receptors (McCullumsmith et al., 2007; Fountoulakis, 2012) and polymorphisms in genes coding for glutamate receptors (Itokawa et al., 2003; Fiorentino et al., 2014; Kandaswamy et al., 2014) have also been reported in bipolar patients. It was found that both doses of lithium were effective in preventing neuronal cell death; higher dose was slightly more effective than the lower dose. From our study, it appears that the higher dose of lithium is neuroprotective and its clinical side effects may be associated with actions other than protecting neurons.

When dendritic morphology was studied, it was found that both doses of lithium increased dendritic length and number. As has been reported, stress plays a major role in mood disorders (Watson et al., 2004) and impaired stress response is associated with hyperglutamatergic state in BD (Zarate et al., 2006). Both stress and hyperglutamatergic state can lead to alterations in spine density and number (Sapolsky, 2000). From our data, it appears that by restoring glutamate-induced changes in neuronal morphology, lithium exerts its neuroprotective action.

BDNF, a molecule implicated in neuronal survival and synaptic plasticity, has been shown to be less expressed in the brain of bipolar patients (Kapczinski et al., 2008). Also, in hippocampus and amygdala of rats showing manic behavior, the expression of BDNF is decreased (Jornada et al., 2010). Under both conditions, lithium normalizes the decreased level of BDNF (Jornada et al., 2010; Wu et al., 2014). As with these studies, the present study also demonstrates that lithium is highly effective in increasing the level of BDNF in hippocampal neurons. To further examine the mechanism of lithium-induced higher expression of BDNF, various BDNF transcripts were examined. The BDNF gene in rats consists of nine exons; out of which each exon I, II, IV and VI encodes a 5'-UTR of the BDNF transcript (Aid et al., 2007). When examined, it was found that both 1 and $2 \mathrm{mM}$ doses of lithium increased the expression of selective exon IV. On the other hand, the expression of other exons (I, II, and VI) were not affected. The present study thus suggests that exon IV-containing BDNF transcripts are responsible for total BDNF expression by lithium.

Gene expression in the nervous system can be modulated by various mechanisms. One of the most prominent mechanisms is through epigenetic modifications. In the present study, it was examined whether increased expression of BDNF gene by lithium was modulated via DNA methylation of BDNF exons. Using methylation-specific primers, it was observed that lithium significantly decreased the methylation of the same specific promoter, i.e., promoter IV, which was found to be elevated in hippocampal neurons treated with lithium. The methylation of other promoters such as I, II, and IV was not altered. These results demonstrate that increased expression of BDNF gene is associated with hypomethylation mediated by lithium. Recently, D'Addario et al. (2012) reported that BDNF expression is downregulated in bipolar patients, which was associated with hypermethylation of the BDNF promoter region. These investigators did not study which specific promoter region of BDNF was altered; nevertheless, from the present study, it appears that lithium's clinical efficacy could be associated with alteration in the methylation of the exon IV BDNF transcript.

The present study also shows that lithium dose dependently increased the expression of antiapoptotic genes $\mathrm{Bcl} 2$ and $\mathrm{Bcl}$ XL. On the other hand, lithium decreased expression of pro-apoptotic genes Bad, Bax, and caspase 3. Both the doses were effective in lowering Bad and caspase 3; however, the lower dose was ineffective on Bax. Thus, neuroprotective mechanisms of lithium could also be attributed to its action on apoptotic regulatory genes. Interestingly, a recent study shows that bipolar patients who respond to lithium show increased ratio of anti- to pro-apoptotic 
genes in blood cells, whereas patients who do not respond to lithium had no significant effect (Lowthert et al., 2012). Thus, it is quite possible that effects on pro- and anti-apoptotic genes may be a prerequisite for lithium action in clinical response to BD.

The mechanism by which lithium modulates the transcription of pro- and anti-apoptotic genes is not clear; however, there may be several possibilities. One could be that BDNF-induced activation of ERK signaling may lead to increased expression of these genes. For example, BCL2 gene contains binding sites for cyclicAMP response element binding protein, a transcription factor that is activated by ERK1/2. Interestingly, lithium has earlier been shown to upregulate ERK expression in cultured cells and in frontal cortex and hippocampus of rat (Chen and Manji, 2006). Lithium also upregulates the expression of BAG-1, a gene that binds to and increases the activity of BCL2 (Zhou et al., 2005). Thus, the effect of lithium on BCL2 could be associated with increased expression of BAG-1. The other possibility could be of increased RNA polymerase activity and thereby increased gene expression by lithium. Further studies will be needed to examine such mechanisms.

Overall, this study provides several mechanisms by which lithium may exert its neuroprotective action. Most prominently, its action on DNA methylation of promoter IV of BDNF and on apoptotic regulatory proteins appears to be directly related to its neuroprotective action. Another point to be noted is that although done in in-vitro, nevertheless, our study clearly shows that even higher dose was effective in protecting neurons. Paradoxically, the higher doses $>2 \mathrm{mM}$ have been shown to have several side effects; however, they do not appear to be associated with neurotoxicity as $2 \mathrm{mM}$ was effective in reversing glutamate-induced neural viability and protecting neurons. These studies must take into account the limitations presented by an invitro study and needs to be validated in in-vivo to fully evaluate lithium's neuroprotective activity in the human population.

\section{ACKNOWLEDGMENT}

We are thankful for Dr. Lech Keidrowaski for preparing hippocampal cultured neurons.

\section{REFERENCES}

Aid, T., Kazantseva, A., Piirsoo, M., Palm, K., and Timmusk, T. (2007). Mouse and rat BDNF gene structure and expression revisited. J. Neurosci. Res. 85, 525-535. doi: 10.1002/jnr.21139

Brambilla, P., Glahn, D. C., Balestrieri, M., and Soares, J. C. (2005). Magnetic resonance findings in bipolar disorder. Psychiatr. Clin. North Am. 28, 443-467. doi: 10.1016/j.psc.2005.01.006

Chang, K., Karchemskiy, A., Barnea-Goraly, N., Garrett, A., Simeonova, D. I., and Reiss, A. (2005). Reduced amygdalar gray matter volume in familial pediatric bipolar disorder. J. Am. Acad. Child. Adolesc. Psychiatry 44, 565-573. doi: 10.1097/01.chi.0000159948.75136.0d

Chen, G., and Manji, H. K. (2006). The extracellular signal-regulated kinase pathway: an emerging promising target for mood stabilizers. Curr. Opin. Psychiatry 19, 313-323. doi: 10.1097/01.yco.0000218604.63463.cd

Cunha, A. B., Frey, B. N., Andreazza, A. C., Goi, J. D., Rosa, A. R., Gonçalves, C. A., et al. (2006). Serum brain-derived neurotrophic factor is decreased in bipolar disorder during depressive and manic episodes. Neurosci. Lett. 398, 215-219. doi: 10.1016/j.neulet.2005.12.085

D’Addario, C., Dell'Osso, B., Palazzo, M. C., Benatti, B., Lietti, L., Cattaneo, E., et al. (2012). Selective DNA methylation of BDNF promoter in bipolar disorder: differences among patients with BDI and BDII. Neuropsychopharmacology 37, 1647-1655. doi: 10.1038/npp.2012.10
Drevets, W. C. (2001). Neuroimaging and neuropathological studies of depression: implications for the cognitive-emotional features of mood disorders. Curr. Opin. Neurobiol. 11, 240-249. doi: 10.1016/S0959-4388(00)00203-8

Engel, S. R., Creson, T. K., Hao, Y., Shen, Y., Maeng, S., Nekrasova, T., et al. (2009). The extracellular signal-regulated kinase pathway contributes to the control of behavioral excitement. Mol. Psychiatry. 14, 448-461. doi: 10.1038/sj.mp.4002135.

Fiorentino, A., Sharp, S. I., and McQuillin, A. (2014). Association of rare variation in the glutamate receptor gene SLC1A2 with susceptibility to bipolar disorder and schizophrenia. Eur. J. Hum. Genet. doi: 10.1038/ejhg.2014.261. [Epub ahead of print].

Fountoulakis, K. N. (2012). The possible involvement of NMDA glutamate receptor in the etiopathogenesis of bipolar disorder. Curr. Pharm. Des. 18, 1605-1608. doi: 10.2174/138161212799958585

Gao, Y., Galante, M., El-Mallakh, J., Nurnberger, J. I. Jr., Delamere, N. A., Lei, Z., et al. (2012). BDNF expression in lymphoblastoid cell lines carrying BDNF SNPs associated with bipolar disorder. Psychiatr. Genet. 22, 253-255. doi: 10.1097/YPG.0b013e328353ae66

Gigante, A. D., Young, L. T., Yatham, L. N., Andreazza, A. C., Nery, F. G., Grinberg, L. T., et al. (2011). Morphometric post-mortem studies in bipolar disorder: possible association with oxidative stress and apoptosis. Int. J. Neuropsychopharmacol. 14, 1075-1089. doi: 10.1017/S146114571000146X

Gildengers, A. G., Butters, M. A., Aizenstein, H. J., Marron, M. M., Emanuel, J., Anderson, S. J., et al. (2014). Longer lithium exposure is associated with better white matter integrity in older adults with bipolar disorder. Bipolar Disord. doi: 10.1111/bdi.12260. [Epub ahead of print].

Glitz, D. A., Manji, H. K., and Moore, G. J. (2002). Mood disorders: treatment-induced changes in brain neurochemistry and structure. Semin. Clin. Neuropsychiatry 7, 269-280. doi: 10.1053/scnp.2002.35226

Hashimoto, K., Sawa, A., and Iyo, M. (2007). Increased levels of glutamate in brains from patients with mood disorders. Biol. Psychiatry 62, 1310-1316. doi: 10.1016/j.biopsych.2007.03.017

Hassel, B., and Dingledine, R. (2006). "Glutamate," in Basic Neurochemistry: Molecular, Cellular, and Medical Aspects, eds G. J. Siegel, R. W. Albers, S. T. Brady, and D. L. Price (San Diego, CA: Academic Press), 267-290.

Hoekstra, R., Fekkes, D., Loonen, A., Pepplinkhuizen, L., Tuinier, S., and Verhoeven, W. (2006). Bipolar mania and plasma amino acids: increased levels of glycine. Eur. Neuropsychopharmacol. 16, 71-77. doi: 10.1016/j.euroneuro.2005.06.003

Hoshi, M., Sato, M., Matsumoto, S., Noguchi, A., Yasutake, K., Yoshida, N., et al. (2003). Spherical aggregates of beta-amyloid (amylospheroid) show high neurotoxicity and activate tau protein kinase I/glycogen synthase kinase-3beta. Proc. Natl. Acad. Sci. U.S.A. 100, 6370-6375. doi: 10.1073/pnas. 1237107100

Huang, E. J., and Reichardt, L. F. (2001). Neurotrophins: roles in neuronal development and function. Annu. Rev. Neurosci. 24, 677-736. doi: 10.1146/annurev.neuro.24.1.677

Itokawa, M., Yamada, K., Iwayama-Shigeno, Y., Ishitsuka, Y., Detera-Wadleigh, S., and Yoshikawa, T. (2003). Genetic analysis of a functional GRIN2A promoter (GT)n repeat in bipolar disorder pedigrees in humans. Neurosci. Lett. 345, 5356. doi: 10.1016/S0304-3940(03)00501-9

Jornada, L. K., Moretti, M., Valvassori, S. S., Ferreira, C. L., Padilha, P. T., Arent, C. O., et al. (2010). Effects of mood stabilizers on hippocampus and amygdala BDNF levels in an animal model of mania induced by ouabain. J. Psychiatr. Res. 44, 506-510. doi: 10.1016/j.jpsychires.2009.11.002

Kandaswamy, R., McQuillin, A., Curtis, D., and Gurling, H. (2014). Allelic association, DNA resequencing and copy number variation at the metabotropic glutamate receptor GRM7 gene locus in bipolar disorder. Am. J. Med. Genet. B Neuropsychiatr. Genet. 165, 365-372. doi: 10.1002/ajmg.b.32239

Kapczinski, F., Frey, B. N., Kauer-Sant'Anna, M., and Grassi-Oliveira, R. (2008). Brain-derived neurotrophic factor and neuroplasticity in bipolar disorder. Expert Rev. Neurother. 8, 1101-1113. doi: 10.1586/14737175.8.7.1101

Karege, F., Perroud, N., Schürhoff, F., Méary, A., Marillier, G., Burkhardt, S., et al. (2010). Association of AKT1 gene variants and protein expression in both schizophrenia and bipolar disorder. Genes Brain Behav. 9, 503-511. doi: 10.1111/j.1601-183X.2010.00578.x

Lowthert, L., Leffert, J., Lin, A., Umlauf, S., Maloney, K., Muralidharan, A., et al. (2012). Increased ratio of anti-apoptotic to pro-apoptotic $\mathrm{Bcl} 2$ gene-family members in lithium-responders one month after treatment initiation. Biol. Mood Anxiety Disord. 2:15. doi: 10.1186/2045-5380-2-15 
Lubin, F. D., Roth, T. L., and Sweatt, J. D. (2008). Epigenetic regulation of BDNF gene transcription in the consolidation of fear memory. J. Neurosci. 28, 10576-10586. doi: 10.1523/JNEUROSCI.1786-08.2008

Lucken-Ardjomande, S., and Martinou, J. C. (2005). Regulation of Bcl-2 proteins and of the permeability of the outer mitochondrial membrane. C. R. Biol. 328, 616-631. doi: 10.1016/j.crvi.2005.05.002

Magno, L. A., Miranda, D. M., Neves, F. S., Pimenta, G. J., Mello, M. P., De Marco, L. A., et al. (2010). Association between AKT1 but not AKTIP genetic variants and increased risk for suicidal behavior in bipolar patients. Genes Brain Behav. 9, 411-418. doi: 10.1111/j.1601-183X.2010.00571.x

McCullumsmith, R., Kristiansen, L., Beneyto, M., Scarr, E., Dean, B., and MeadorWoodruff, J. (2007). Decreased NR1, NR2A, and SAP102 transcript expression in the hippocampus in bipolar disorder. Brain Res. 1127, 108-118. doi: 10.1016/j.brainres.2006.09.011

Monteleone, P., Serritella, C., Martiadis, V., and Maj, M. (2008). Decreased levels of serum brain-derived neurotrophic factor in both depressed and euthymic patients with unipolar depression and in euthymic patients with bipolar I and II disorders. Bipolar Disord. 10, 95-100. doi: 10.1111/j.1399-5618.2008. 00459. $\mathrm{x}$

Moore, G. J., Bebchuk, J. M., Hasanat, K., Chen, G., Seraji-Bozorgzad, N., Wilds, I. B., et al. (2000b). Lithium increases $\mathrm{N}$-acetyl-aspartate in the human brain: in vivo evidence in support of bcl-2's neurotrophic effects? Biol. Psychiatry 48, 1-8. doi: 10.1016/S0006-3223(00)00252-3

Moore, G. J., Bebchuk, J. M., Wilds, I. B., Chen, G., and Manji, H. K. (2000a). Lithium-induced increase in human brain grey matter. Lancet 356, 1241-1242. doi: 10.1016/S0140-6736(00)02793-8

Nock, M. K., Hwang, I., Sampson, N., Kessler, R. C., Angermeyer, M., Beautrais, A., et al. (2009). Cross-national analysis of the associations among mental disorders and suicidal behavior: findings from the WHO World Mental Health Surveys. PLoS Med 6:e1000123. doi: 10.1371/journal.pmed.1000123

Pompili, M., Innamorati, M., Gonda, X., Erbuto, D., Forte, A., Ricci, F., et al. (2013). Characterization of patients with mood disorders for their prevalent temperament and level of hopelessness. J. Affect Disord. 166, 285-291. doi: 10.1016/j.jad.2014.05.018

Rybakowski, J. K. (2011). Lithium in neuropsychiatry: a 2010 update. World J. Biol. Psychiatry 12, 340-348. doi: 10.3109/15622975.2011.559274

Sapolsky, R. M. (2000). Glucocorticoids and hippocampal atrophy in neuropsychiatric disorders. Arch. Gen. Psychiatry 57, 925-935. doi: 10.1001/archpsyc.57.10.925

Savitz, J. B., Price, J. L., and Drevets, W. C. (2014). Neuropathological and neuromorphometric abnormalities in bipolar disorder: view from the medial prefrontal cortical network. Neurosci. Biobehav. Rev. 42C, 132-147. doi: 10.1016/j.neubiorev.2014.02.008

Schroeder, E., Gao, Y., Roberts, R. J., and El-Mallakh, R. S. (2011). Recognition and management of bipolar depression. J. Clin. Outcomes Manag. 18, 515-525.

Schulze-Osthoff, K., Ferrari, D., Los, M., Wesselborg, S., and Peter, M. E. (1998). Apoptosis signaling by death receptors. Eur. J. Biochem. 254, 439-459. doi: 10.1046/j.1432-1327.1998.2540439.x
Soeiro-de-Souza, M. G., Salvadore, G., Moreno, R. A., Otaduy, M. C., Chaim, K. T., Gattaz, W. F., et al. (2013). Bcl-2 rs956572 polymorphism is associated with increased anterior cingulate cortical glutamate in euthymic bipolar I disorder. Neuropsychopharmacology 38, 468-475. doi: 10.1038/npp.2012.203

Visnjic, D., and Banfic, H. (2007). Nuclear phospholipid signaling: phosphatidylinositol-specific phospholipase $\mathrm{C}$ and phosphoinositide 3-kinase. Pflugers Arch. 455, 19-30. doi: 10.1007/s00424-007-0288-1

Watson, S., Gallagher, P., Ritchie, J., Ferrier, I., and Young, A. (2004). Hypothalamic-pituitary-adrenal axis function in patients with bipolar disorder. Br. J. Psychiatry 184, 496-502. doi: 10.1192/bjp.184.6.496

Wilson, B. E., Mochon, E., and Boxer, L. M. (1996). Induction of bcl-2 expression by phosphorylated CREB proteins during B-cell activation and rescue from apoptosis. Mol. Cell Biol. 16, 5546-5556.

Wu, R., Fan, J., Zhao, J., Calabrese, J. R., and Gao, K. (2014). The relationship between neurotrophins and bipolar disorder. Expert Rev. Neurother. 14, 51-65. doi: 10.1586/14737175.2014.863709

Yildiz-Yesiloglu, A., and Ankerst, D. P. (2006). Review of $1 \mathrm{H}$ magnetic resonance spectroscopy findings in major depressive disorder: a meta-analysis. Psychiatry Res. 147, 1-25. doi: 10.1016/j.pscychresns.2005.12.004

Young, W. (2009). Review of lithium effects on brain and blood. Cell Transplant. 18, 951-975. doi: 10.3727/096368909X471251

Yuan, J., and Yankner, B. A. (2000). Apoptosis in the nervous system. Nature 407, 02-809. doi: 10.1038/35037739

Zarate, C. J., Singh, J., and Manji, H. (2006). Cellular plasticity cascades: targets for the development of novel therapeutics for bipolar disorder. Biol. Psychiatry 59, 1006-1020. doi: 10.1016/j.biopsych.2005.10.021

Zhou, R., Gray, N. A., Yuan, P., Li, X., Chen, J., Chen, G., et al. (2005). The antiapoptotic, glucocorticoid receptor cochaperone protein BAG-1 is a long-term target for the actions of mood stabilizers. J. Neurosci. 25, 4493-4502. doi: 10.1523/JNEUROSCI.4530-04.2005

Conflict of Interest Statement: The authors declare that the research was conducted in the absence of any commercial or financial relationships that could be construed as a potential conflict of interest.

Received: 05 December 2014; paper pending published: 22 December 2014; accepted: 25 December 2014; published online: 14 January 2015.

Citation: Dwivedi T and Zhang H (2015) Lithium-induced neuroprotection is associated with epigenetic modification of specific BDNF gene promoter and altered expression of apoptotic-regulatory proteins. Front. Neurosci. 8:457. doi: 10.3389/fnins. 2014.00457

This article was submitted to Neuropharmacology, a section of the journal Frontiers in Neuroscience.

Copyright (C) 2015 Dwivedi and Zhang. This is an open-access article distributed under the terms of the Creative Commons Attribution License (CC BY). The use, distribution or reproduction in other forums is permitted, provided the original author(s) or licensor are credited and that the original publication in this journal is cited, in accordance with accepted academic practice. No use, distribution or reproduction is permitted which does not comply with these terms. 